\title{
Developing a Test to Measure Drawing a Shape-Schema and Making a Table Skills of Prospective Teachers
}

\author{
Ibrahim Yuksel ${ }^{1 \rtimes}$ \\ Muhammed Ali Savas ${ }^{2}$ \\ ${ }^{\prime}$ Gazi University, Gazi Faculty of Education Ankara, Turkey \\ Email: ibrahimyuksel7@hotmail.com Tel:+905063444844 \\ -Akcamescit Secondary School, Centrum, Bartin, Turkey \\ Email:mali.savas@gmail.com Tel:+905413772909
}

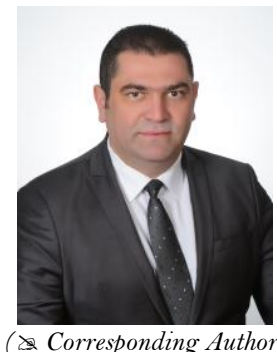

( Corresponding Author)

\begin{abstract}
In this research, it is aimed to develop a valid and reliable test to determine the drawing a shape-schema and making a table levels of prospective teachers at Mathematics and Science Education, Turkish and Social Sciences Education and Basic Education Departments. In this process, a comprehensive item pool has been prepared with the table of specifications regarding the gains to be measured and the highest possible number of substances has been produced for each gain. The items were prepared according to the characteristics of the target group. A pool of 18 items consisting of drawing a shape-schema and making a table subdimensions was formed from the methods used in problem solving in this study. Expert opinions were taken to ensure the validity of the test. Two experts in the field of science, two in the field of classroom teaching and two in the field of social sciences were interviewed. In the field of language and expression, two experts were consulted. Based on the opinions of the experts, 6 items were excluded from the test. The 12-item test was applied to 13 prospective teachers who were educated at a public university, which has an important place in the field of education, and who were willing to participate voluntarily and randomly selected. Arrangements have been made for a more comprehensible expression of items after the pilot implementation. After the pilot test, the Cronbach Alpha reliability coefficient of the 10-item test was, 73. The duration of completion of the test questions was 60 minutes for 12 items. Then, when two items were excluded from the test, the mean time was determined as 54 minutes.
\end{abstract}

Keywords: Developing a test, Drawing a shape-schema, Making a table, Prospective teachers.

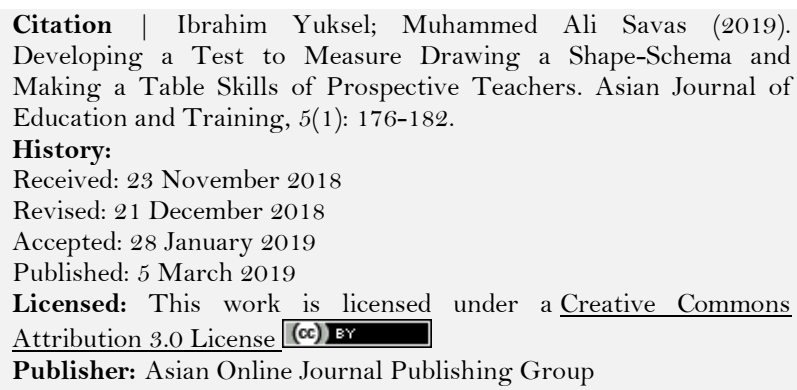

Contribution/Acknowledgement: Both authors contributed to the conception and design of the study.

Funding: This study received no specific financial support.

Competing Interests: The authors declare that they have no conflict of interests.

Transparency: The authors confirm that the manuscript is an honest, accurate, and transparent account of the study was reported; that no vital features of the study have been omitted; and that any discrepancies from the study as planned have been explained.

Ethical: This study follows all ethical practices during writing. 


\section{Contents}

1. Introduction

\section{Introduction}

In today's information age, rapid changes in science and technology affect the expectations and needs of the society. This situation requires constant change and development of individuals. In light of this, the main objective of the countries is to raise individuals who are physically, mentally, emotionally and socially healthy, self-confident and who have problem-solving skills (Aksut, 2015). Many problem solving strategies are mentioned in sources (Tertemiz and Cakmak, 2001; Sulak, 2005). As a result of scanning, the seven most common problem solving strategies were found: 1-) Making a systematic list 2-) Drawing a shape-schema 3-) Making a Table 4) Writing a mathematical sentence 5-) Reasoning 6-) Regression 7-) Prediction-control (Kilic, 2009). In this research, we used drawing a shape-schema and making a table strategy and we can explain these strategies as follows.

1. Drawing a shape-schema: A figure, diagram or graphic that is appropriate to the problem, is also an important step in solving the problem; because this behavior provides great convenience to see the relationship between the given and the desired; therefore, it is the first stage for the student to develop a strategy for solution. In this strategy, real events, objects, people and situations are represented by simple figures, symbols (x, o), dots and so on (Baykul, 2009).

2. Making a table: Sometimes when the numbers of the problem are digitized, the order of these numbers shows a certain rule. When these numbers are tabulated, the rule becomes more easily visible (Tertemiz and Cakmak, 2003). In this strategy, it is important to find the right title in the line and column headings of the table. Using the table strategy may be reading or completing a given table, interpreting the table with questions, collecting information and organizing them in the table (Sulak, 2005).

It's necessary to use problem solving skills well against problems encountered in daily life. In this sense, activities can be done in many areas related to drawing a shape-schema and making a table. In this study, we used the science concepts in daily life. Geometric-Mechanical Games and Verbal Games from mind games have an important role in the development of our problem solving skills. One of the tools that can be used for educational purposes and which can influence the thinking skills of the learners such as problem solving (Ott and Pozzi, 2012) and general school success (Bottino et al., 2013) is the Mind Games. Mind Games require individuals to use some strategies and logical problem solving skills in solving problems (Alessi and Trollip, 2001). With the development of problem solving skills, the individual will be able to develop solutions, gain self-confidence and time management. To recognize and develop the intelligence potential, to develop different and original strategies in the face of the problem, to make fast and accurate decisions, to develop a systematic thinking structure, to learn individual and team work and to improve the skills to work in the competitive environment are purposed with Geometric-Mechanical Games and Verbal Games (Board of Education and Discipline (BOEAD), 2013). However, these developments are faster in primary and secondary school years. Therefore, the opinions of prospective teachers in primary and secondary schools are important. To measure Science Teaching and Classroom Teaching prospective teachers' levels between drawing a shape-schema and making a table in geometric-mechanical games and verbal games in terms of the science subjects used in daily life is important for the development of the students who will be educated in the future.

In Geometric-Mechanical Games and Verbal Games, it is necessary to choose cascading curriculum due to the difference of students' level of development. Cascading curriculum is a program showing a progressive relationship from simple to complex, from easy to difficult, from concrete to abstract, from known to unknown, from close to far. These steps follow a path from the understanding of basic knowledge and skills to the acquisition of high-level thinking skills (BOEAD, 2013). The cascading curriculum includes three basic steps:

1st step-Beginning Level: It includes learning the rules of the games, to gain basic knowledge and skills, to play beginner games and to solve puzzles.

2nd step-Intermediate Level: It involves making logical inferences, starting from the right place in the puzzles, applying basic strategies in strategy games, playing mid-level games and solving puzzles.

3rd step-Advanced Level: It involves high level knowledge and skills such as analyzing, putting forward original strategies, evaluating, generalizing. Playing advanced games, solving puzzles and benefiting from the experiences of others are in this stage (BOEAD, 2013). 
Table-1. Units in the program were designed for different game types.

\begin{tabular}{|c|c|c|c|}
\hline Level/Games & Beginning Level & Intermediate Level & Advanced Level \\
\hline $\begin{array}{l}\text { Geometric - } \\
\text { Mechanical } \\
\text { Games }\end{array}$ & $\begin{array}{l}\text { 1. Games that are non- } \\
\text { systematic and can be } \\
\text { solved with few trial and } \\
\text { error. }\end{array}$ & $\begin{array}{l}\text { 1. Games that can be solved } \\
\text { with few and systematic or } \\
\text { intuitive trial and error. } \\
\text { 2. Games that can be solved by } \\
\text { finding a single key idea. }\end{array}$ & $\begin{array}{l}\text { 1. Games that can be solved with } \\
\text { numerous and systematic or intuitive } \\
\text { trial and error. } \\
\text { 2. Games that can be solved by using } \\
\text { more than one key ideas. }\end{array}$ \\
\hline $\begin{array}{l}\text { Verbal } \\
\text { Games }\end{array}$ & $\begin{array}{l}\text { 1. Games in which } \\
\text { progress is made by } \\
\text { listing all possibilities. }\end{array}$ & $\begin{array}{l}\text { 1. Games in which words } \\
\text { appropriate to the rule are } \\
\text { derived by using vocabulary. } \\
\text { 2. Games that game-specific } \\
\text { basic strategies are used. }\end{array}$ & $\begin{array}{l}\text { 1. Games in which researches based on } \\
\text { intelligent predictions to reach a } \\
\text { solution are made. } \\
\text { 2. Games that the player developed } \\
\text { and used game-specific strategy. }\end{array}$ \\
\hline
\end{tabular}

Source: BOEAD (2013).

The focus of the program is on developing students' problem solving, communication and reasoning, selfregulation and psychomotor skills and affective characteristics. The following objectives should be considered in the implementation of games for the development of problem solving skills:

1. Developing the ability to question the nature of the problem to fully understand the problems,

2. Developing various problem solving methods and strategies by using different mind games,

3. Developing students' self-confidence through experience in problem solving,

4. Developing fast and effective decision-making skills,

5. Developing a questioning and skeptical approach to solve problems,

6. Helping to recognize their individual strengths and weaknesses (BOEAD, 2013).

Problem Statement: The general problem statement of this research can be expressed as "Development of a test to determine the drawing a shape-schema and making a table levels of prospective teachers at Mathematics and Science Education, Turkish and Social Sciences Education and Basic Education Departments".

Purpose of the Study: In this research, it is aimed to develop a valid and reliable test to determine the drawing a shape-schema and making a table levels of prospective teachers at Mathematics and Science Education, Turkish and Social Sciences Education and Basic Education Departments.

Considering that the people who will teach drawing a shape-schema and making a table skills to the students are the teachers, it is necessary that prospective teachers should have these skills firstly. However, there has not been a sufficient study on the drawing a shape-schema and making a table skills of prospective teachers in our country. In this context, in this research it is aimed to determine the levels of prospective teachers studying in different departments.

\section{Method}

This research was carried out with 111 randomly selected and volunteer prospective teachers studying at the faculty of education of a state university, which has an important place in the education in Turkey.

There is not enough study to measure the drawing a shape-schema and making a table skills of prospective teachers in Mathematics and Science Education, Turkish and Social Sciences Education and Basic Education Departments. "Success Test Development Stages Rubric" prepared by the researchers was used to obtain the data. While preparing this rubric, literature review was made and success test development stages were determined as follows.

Objective determination and literature review: While preparing a test of achievement, at first the purpose of the test was determined and a literature review of the test was conducted.

Table of specifications: Table of specifications provides guidance in ensuring the scope validity of the measuring instrument. In order to show clearly which cognitive areas the questions in the item pool are, a table of specifications has been formed.

Item pool (Question generation): The process of creating a draft success test has started after the literature review. The most important stage of the success test preparation process is generating questions. In this process, a comprehensive item pool has been prepared with the table of specifications regarding the gains to be measured and the highest possible numbers of substances have been produced for each gain. The items were prepared according to the characteristics of the target group. In order to measure these skills, a pool of 18 items consisting of drawing a shape/schema and making a table sub-dimensions was formed from the methods used in problem solving in this study.

After the items were created, the test was submitted to expert opinions for the studies of the scope validity (Alpar, 2012). 
Expert opinions and studies of the scope validity: After the preparation of the item pool, it was reviewed by the experts in terms of its scope, scientific, language and expression and the technical characteristics of the items. For this purpose, there were 6 field experts, 2 language experts and 1 measurement and evaluation expert among the experts (Metin, 2014). After the item pool the content validity of the written items was determined. One of the ways of demonstrating the scope validity, which is an indication that the items in the test can reveal the purposed features, is to get expert opinion (Buyukozturk, 2010). Expert opinions were taken to ensure the validity of the test. Two experts in the field of science, two in the field of classroom teaching and two in the field of social sciences were interviewed. In the field of language and expression, two experts were consulted. According to the opinions of the experts, changes were made by the researchers in some items. Drawing a Shape-Schema (Square and T Tangram) - Making a Table (Anagram and Word Hunt) Test (DSMTT) was prepared for pilot application.

Pilot application: The scope validity studies carried out after the expert opinions will be completed by the extraction or correction of some items and addition of new items. After this point, the draft success test should be applied to a group with similar characteristics to the main group (Gorard, 2010). There are different opinions regarding the number of groups to be selected for the pilot application in the literature. According to these views, it changes 5 or 10 times the number of items. Based on the opinions of the experts, 6 items were excluded from the test. The 12-item test was applied to 13 prospective teachers who were educated at a public university, which has an important place in the field of education, and who were willing to participate voluntarily and who were randomly selected. Arrangements have been made for a more comprehensible expression of items after the pilot implementation.

Item analyzes: The item discrimination and item difficulty indexes of each item were calculated and reported within the scope of item analyzes. The fact that the item discrimination and item difficulty indexes of each item are between the values in the literature indicates that the test is a valid test. The item discrimination index shows the power of separating individuals who know and don't know the answer of the item. Statistically, it is a correlation between the total test scores and item scores, and the index ranges from -1 to +1 . The negativity of this value is a proof that the item is discriminating the individuals reversely and negative items cannot be included in the test (Fan and Sun, 2013). In the literature, it is stated that this value should be 0.30 and above (Hinkle et al., 2003).

The item difficulty index is the ratio of the number of correct respondents for an item to total number of people participating in the test. In the achievement tests, it is recommended that the difficulty value of the item be homogeneous between 0.20 and 0.80 (Christensen et al., 2015).

Reliability analysis: The reliability must be tested after completing the validity of the achievement test. Salkind (2015) defined reliability as a measure of how consistent the measurements of a test or any tool used to make a measurement. There are many ways to calculate the reliability value that we can call internal consistency of the test. These are calculated with Cronbach alpha coefficient (Salkind, 2015).

The DSMTT was controlled by scoring rubrics as indicated in Tables 2, 3, 4 and 5 .

Table-2. Square Tangram Scoring Rubric.

\begin{tabular}{c|l}
\hline Scores & Scoring Criteria \\
\hline 4 & $\begin{array}{l}\text { Drawings in which } 7 \text { parts are shown and the drawing is complete and the relationship between the parts is } \\
\text { proportionally correct }\end{array}$ \\
\hline 3 & $\begin{array}{l}\text { Drawings in which } 5 \text { or } 6 \text { parts are shown and the whole drawing is incomplete because of the missing parts } \\
\text { and the relationship between parts is proportionally correct }\end{array}$ \\
\hline 2 & $\begin{array}{l}\text { Drawings in which 4 or less parts are shown and the whole drawing is incomplete because of the missing } \\
\text { parts and the relationship between the parts is proportionally correct }\end{array}$ \\
\hline 1 & Drawings in which the drawing is made as a whole without any parts attached to the outer frame \\
\hline 0 & No drawings or holistic drawings unsuitable for the outer frame \\
\hline
\end{tabular}

Table-3. T Tangram Scoring Rubric.

\begin{tabular}{c|l}
\hline Scores & Scoring Criteria \\
\hline 4 & $\begin{array}{l}\text { Drawings in which 4 parts are shown and the whole drawing is complete and the relationship between the } \\
\text { parts is proportionally correct }\end{array}$ \\
\hline 3 & $\begin{array}{l}\text { Drawings in which } 3 \text { parts are shown and the whole drawing is incomplete because of the missing parts } \\
\text { and the relationship between the parts is proportionally correct }\end{array}$ \\
\hline 2 & $\begin{array}{l}\text { Drawings in which } 2 \text { or less parts are shown and the whole drawing is incomplete because of the missing } \\
\text { parts and the relationship between the parts is proportionally correct }\end{array}$ \\
\hline 1 & Drawings in which the drawing is made as a whole without any parts attached to the outer frame \\
\hline 0 & No drawings or holistic drawings unsuitable for the outer frame \\
\hline
\end{tabular}


Table-4. Word Hunt Scoring Rubric.

\begin{tabular}{c|l}
\hline Scores & Scoring Criteria \\
\hline 4 & Tables in which all given words are complete and the password sentence is correct \\
\hline 3 & $\begin{array}{l}\text { Tables in which all given words are complete and the password sentence is incorrect } \\
\text { Tables in which at least half of all given words are correct and password sentence is correct }\end{array}$ \\
\hline 2 & Tables in which at least half of all given words are correct and password sentence is incorrect \\
\hline 1 & Tables in which at least a quarter of all given words are correct and password sentence is incorrect \\
\hline 0 & $\begin{array}{l}\text { No tables } \\
\text { Tables in which nearly a quarter of all given words are correct and password sentence is incorrect }\end{array}$ \\
\hline & \multicolumn{1}{c}{ Table-5. Anagram Scoring Rubric. } \\
\hline Scores & Scoring Criteria \\
\hline 4 & Tables in which all given words are complete or the password sentence is correct \\
\hline 2 & Tables in which all given words are complete and the password sentence is incorrect \\
\hline 1 & Tables in which at least half of all given words are correct and password sentence is incorrect \\
\hline 0 & $\begin{array}{l}\text { No tables } \\
\text { Tables in which nearly a quarter of all given words are correct and password sentence is incorrect }\end{array}$ \\
\hline
\end{tabular}

The cut-off points for the DSMTT were arranged by the researchers in Table 6 according to the opinions of the experts.

Table-6. The Cut-off Points for the DSMTT.

\begin{tabular}{c|l|c|l}
\hline Items & Cut-off Points & Items & Cut-off Points \\
\hline 1 & 4 points successful; 3 points and less failed & 7 & 4 points successful; 3 points and less failed \\
\hline 2 & 4 points successful; 3 points and less failed & 8 & 1 point and more successful \\
\hline 3 & 1 point and more successful & 9 & 1 point and more successful \\
\hline 4 & 4 points successful; 3 points and less failed & 10 & 3 points successful; 2 points and less failed \\
\hline 5 & 1 point and more successful & 11 & 3 points successful; 2 points and less failed \\
\hline 6 & 1 point and more successful & 12 & 1 point and more successful \\
\hline
\end{tabular}

The research with 12-item DSMTT was conducted with 111 randomly selected prospective teachers who wish to participate as a volunteer and was studying at the education faculty of a state university in Turkey which has an important place in education. The distribution of 111 prospective teachers by gender is given in Table 7 .

Table-7. Distribution of Prospective Teachers in the Study Group by Gender.

\begin{tabular}{l|c|c|c|c|c|c}
\hline Departments & \multicolumn{2}{|c|}{ Woman } & \multicolumn{2}{c|}{ Man } & \multicolumn{3}{c}{ Total } \\
\hline & $\mathbf{F}$ & $\mathbf{\%}$ & $\mathbf{f}$ & $\mathbf{\%}$ & $\mathbf{f}$ & $\mathbf{\%}$ \\
\hline Mathematics and Science Education & 55 & 49,5 & 10 & 9 & 65 & 58,5 \\
\hline Turkish and Social Sciences Education & 23 & 20,7 & 5 & 4,5 & 28 & 25,2 \\
\hline Basic Education & 17 & 15,3 & 1 & 0,9 & 18 & 14,4 \\
\hline
\end{tabular}

\subsection{Data Analysis}

SPSS 22.0 statistical program was used to analyze the data. The extent to which a measuring instrument can accurately measure the feature it intends to measure without mixing it in any other features is defined as validity (Basol, 2013). "The extent to which the scale can accurately measure an abstract concept (factor) in the context of desired behavior" is defined as construct validity (Buyukozturk, 2010). In this study, the construct validity of the DMSTT test was provided by expert opinions.

\section{Findings}

3.1. Item Difficulty Index

The findings of item difficulty index are given in Table 8. 
Table-8. Item Difficulty Index

\begin{tabular}{c|c|c|c|c|c}
\hline Items & $\mathbf{P}$ & Items & $\mathbf{P}$ & Items & $\mathbf{P}$ \\
\hline 1 &, 79 & 5 &, 57 & 9 &, 51 \\
\hline 2 &, 31 & 6 &, 56 & 10 &, 76 \\
\hline 3 &, 56 & 7 &, 92 & 11 &, 66 \\
\hline 4 &, 65 & 8 &, 77 & 12 &, 47 \\
\hline
\end{tabular}

As a result of the item difficulty indexes, item 2 was difficult in terms of item difficulties, items 3, 5, 6, 9 and 12 were in medium difficulty, items $1,4,8,10$ and 11 were easy and item 7 was very easy.

\subsection{Item Discrimination Index}

Item Discrimination Index gives information about the quality of the item. It gives the degree to which the item can distinguish the low and high scores of the test alone. The correlation between item scores and test scores is obtained by calculating the correlation coefficient. It's the level of a test item and distractings to distinguish between the correct respondents and incorrect respondents. That is, the criterion used to determine whether an item distinguishes students with high levels of achievement in the group from the ones with low levels of achievements. The questions in a test are expected to have high discriminative powers. Items with very low discriminative power must be removed from the test. It's also indicated that relatively easy and difficult items should be included in the tests. Item discrimination shows the extent to which the item distinguishes the individuals with regard to the measured feature (Buyukozturk et al., 2014). The findings of the DSMTT Test item discrimination index are given in Table 9.

Table-9. Item Discrimination Index.

\begin{tabular}{c|c|c|c|c|c}
\hline Items & $\mathbf{r}_{\mathrm{j} \mathbf{x}}$ & Items & $\mathbf{r}_{\mathbf{j} \mathbf{x}}$ & Items & $\mathbf{r}_{\mathbf{j} \mathbf{x}}$ \\
\hline 1 &, 33 & 5 &, 87 & 9 &, 63 \\
\hline 2 &, 40 & 6 &, 87 & 10 &, 40 \\
\hline 3 &, 83 & 7 &, 17 & 11 &, 53 \\
\hline 4 &, 70 & 8 &, 57 & 12 &, 17 \\
\hline
\end{tabular}

When Table 9 was examined, it was determined that the discriminant values of items 7 and 12 in the test were low. For this reason, items 7 and 12 were excluded from the test.

The validity and reliability calculations of the test were made by an expert. The Cronbach alpha coefficient was used to estimate the reliability of the test (Buyukozturk, 2010). Cronbach's alpha coefficients of the test, the items of which shows high correlations with each other, will be high (Tezbasaran, 2008).

The Cronbach Alpha reliability coefficient of the 10-item test after the pilot test was ,73. The duration of completion of the test questions was 60 minutes for 12 items. Then, when two items were excluded from the test, the mean time was determined as 54 minutes.

\section{Conclusion, Discussion and Suggestions}

There may be a single $\alpha$ value determined for each item or an average $\alpha$ value for all items in the scale. The $\alpha$ value obtained for all items indicates the total reliability of the test and the overall acceptance is that this value should be 0,7 and above. Cronbach alpha coefficient values between 0,7 and 0,9 are interpreted to be good and are included in the literature (George and Mallery, 2003).

As a result of the item difficulty indexes, item 2 was difficult in terms of item difficulties, items 3, 5, 6, 9 and 12 were in medium difficulty, items $1,4,8,10$ and 11 were easy and item 7 was very easy. When the test was examined, it was determined that the discriminative values of items 7 and 12 in the test were low. For this reason, items 7 and 12 were excluded from the test. The duration of completion of the test questions was determined as 60 minutes for 12 items. A valid and reliable measurement tool has been developed with expert opinions and statistical results. Then, when two items were excluded from the test, the mean time was 54 minutes. Genç and Kalafat (2007) determined that prospective teachers' problem solving skills differed significantly according to the classes and departments they studied. In this study, a reliable and valid measurement tool has been developed to measure the drawing a shape/schema drawing and making a table skills of prospective teachers in Mathematics and Science Education, Turkish and Social Sciences Education and Basic Education Departments.

In brief, it is seen in the studies and teaching programs that the importance of drawing a shape/schema and making a table in educational activities, teaching activities and daily life increases day by day. For this reason, it is accepted that drawing a shape/schema and making a table is important in problem solving for both 
instructors and teacher candidates. As a result of the findings of the study, the following suggestions can be made to the researchers who wish to work in this field in the future; By selecting a larger sample group, shape/schema and making a table skills of prospective teachers in all departments of education faculties can be examined in terms of different variables. Experimental studies including teaching methods and activities that will improve prospective teachers' drawing a shape/schema and making a table skills can be done.

When prospective teachers are trained, information about drawing a shape/schema and making a table can be given by adding to the course curriculum. In-service training can be given to teachers on drawing a shape/schema and making a table skills.

\section{References}

Aksut, P., 2015. Investigation of the effects of activity based science teaching practices on problem solving skills of 5-6 year old preschool children. PhD Thesis. Abant İzzet Baysal University / Institute of Educational Sciences.

Alessi, S.M. and S.R. Trollip, 2001. Multimedia for learning. 3rd Edn., Boston, MA: Allyn and Bacon.

Alpar, R., 2012. Applied statistics and validity-reliability. Ankara: Detay Publishing.

Basol, G., 2013. Measurement and evaluation in education. Ankara: Pegem Academy Publishing.

Baykul, Y., 2009. Teaching mathematics in primary education (grades 6-8). Ankara: Pegem Academy.

Board of Education and Discipline (BOEAD), 2013. Secondary school and imam hatip secondary school mind games. Available from http://teyd.org.tr/pdf/zekaoyunlari.pdf.

BOEAD, 2013. Secondary school and imam hatip secondary school mind games. Available from http://teyd.org.tr/pdf/zekaoyunlari.pdf

Bottino, R.M., M. Ott and M. Tavella, 2013. Children's performance with digital mind games and evidence for learning behaviour. Information Systems, E-learning, and Knowledge Management Research. Berlin Heidelberg: Springer. pp: 235-243.

Buyukozturk, S., 2010. Manual of data analysis for social sciences. Ankara: Pegem Academy Publishing.

Buyukozturk, S., E.K. Cakmak, O.E. Akgun, S. Karadeniz and F. Demirel, 2014. Scientific research methods. Ankara: Pegem Academy.

Christensen, L.B., R.B. Johnson and L.A. Turner, 2015. Research methods pattern and analysis. A. Aypay (Translation Ed.). Ankara: Anı Publishing.

Fan, X. and S. Sun, 2013. Item response theory. T. Teo (Edt.), In Handbook of quantitative methods for educational research. The Netherlands: Sense Publishers.

Genç, S. and T. Kalafat, 2007. The research on evaluation of prospective teachers' democratic attitudes and problem solving skills according as different variables. Pamukkale University Education Faculty Journal, 2(22): 10-22.

George, D. and P. Mallery, 2003. SPSS for windows step by step: A simple guide and reference. 11.0 update (4th Edn). Boston: Allyn \& Bacon.

Gorard, S., 2010. Quantitative methods in educational research: The role of numbers made easy. London: Bloomsbury Publishing.

Hinkle, D.E., W. Wiersma and S.G. Jurs, 2003. Applied statistic for the behavioral sciences. Boston: Houghton Mifflin Company.

Kilic, C., 2009. The solutions used by the fifth grade students in the solution of mathematical problems. Anadolu University, Institute of Educational Sciences, Elementary Education Department, Ph.D. Thesis, Eskișehir.

Metin, M., 2014. Quantitative data collection tools. M. Metin (Edt.) From theory to practice in scientific research methods in education. Ankara: Pegem Academy.

Ott, M. and F. Pozzi, 2012. Digital games as creativity enablers for children. Behaviour \& Information Technology, 31(10): 10111019.Available at: https://doi.org/10.1080/0144929x.2010.526148.

Salkind, N.J., 2015. Statistics for those who hate statistics. A. Çuhadaroğlu (Trans. Edt.). Ankara: Anı Publishing.

Sulak, S., 2005. The effect of problem solving strategies on problem solving success in primary mathematics lesson. Selcuk University, Institute of Social Sciences, Department of Primary Education, Master Thesis, Konya.

Tertemiz, N. and M. Cakmak, 2001. Teachers' views on the problem solving method in elementary mathematics I. Research Presentation, X. National Congress of Educational Sciences Abant İzzet Baysal University, Faculty of Education. June 7-8. Bolu.

Tertemiz, N. and M. Cakmak, 2003. Problem solving, elementary 1st level math lesson examples. Ankara: Gunduz Education and Publishing.

Tezbasaran, A.A., 2008. Likert type scale preparation guide (third version). Mersin. Available from http://www.academia.edu/1288035/Likert_Tipi_Strength_Preparation_Guide [Accessed May 3, 2017]. 